\title{
Serial assessments of anterior pituitary hormones in a case of mixed histiocytosis representing Langerhans cell histiocytosis overlapping with Erdheim-Chester disease
}

\author{
Kei Ito1, Jun Ito1, Yuki Yamamoto1, Rikako Nakajima1, Masanao Fujii1, Yukino Katakura1, \\ Aiko Muramatsu', Norio Takayashiki², Kazuhiro Toyama ${ }^{3}$, Mineo Kurokawa ${ }^{3}$ and \\ Hiroaki Yagyu(D1 \\ 1Department of Endocrinology and Metabolism, 2Department of Pathology, Tsukuba University Hospital Mito Clinical \\ Education and Training Center, Mito Kyodo General Hospital, Miyamachi, Mito-shi, Ibaraki, Japan, and ${ }^{2}$ Department \\ of Hematology and Oncology, Graduate School of Medicine, The University of Tokyo, Bunkyo-ku, Tokyo, Japan
}

\author{
Correspondence \\ should be addressed \\ to $\mathrm{H}$ Yagyu \\ Email \\ hiroakiyagyu@md.tsukuba. \\ ac.jp
}

\section{Summary}

A 61-year-old man developed central diabetes insipidus caused by mixed histiocytosis $(\mathrm{MH})$ representing Langerhans cell histiocytosis overlapping with Erdheim-Chester disease. Bone, skin, vascular, and retroperitoneal involvements were also observed. Dynamic hormonal testing showed normal responses for anterior pituitary hormones, except for impaired secretion of growth hormone (GH). MRI of the brain showed thickening of the pituitary stalk with slightly reduced signal hyperintensity in the posterior pituitary lobe on T1-weighted imaging. During 2 years of follow-up without radical treatment for $\mathrm{MH}$, imaging studies suggested extension of vascular and retroperitoneal involvements. In contrast, brain MRI did not show any particular interval changes, except for the disappearance of hyperintense signalling in the posterior pituitary lobe. Moreover, no other anterior pituitary dysfunctions beyond GH deficiency emerged during the 2 years of follow-up. The natural history of $\mathrm{MH}$ in this case is described, focusing on serial assessments of pituitary functions using dynamic tests.

\section{Learning points:}

- Erdheim-Chester disease and Langerhans cell histiocytosis overlapping as MH was described, focusing on pituitary functions.

- MH caused both GH deficiency and central diabetes insipidus.

- Despite a lack of radical therapy for $\mathrm{MH}$, no other anterior pituitary dysfunctions emerged for 2 years.

- Radiological images showed no particular interval changes in pituitary stalk lesions, while vascular and retroperitoneal involvements extended.

\section{Background}

Histiocytoses are rare disorders characterised by the accumulation of cells derived from dendritic cells and macrophages (1). Erdheim-Chester disease (ECD) and Langerhans cell histiocytosis (LCH) are subtypes of histiocytosis. ECD mainly affects the skeleton, but it can exhibit involvement of the cardiovascular system and CNS, retroperitoneal fibrosis, and cutaneous manifestations such as xanthelasma. LCH can also affect multiple organs, such as bone, skin, CNS, liver, spleen, and haematopoietic system. 
Both diseases affect the hypothalamic-pituitary portal system and lead to endocrine abnormalities in which central diabetes insipidus (CDI) is often the first endocrine manifestation. Mixed histiocytosis ( $\mathrm{MH})$ is defined as the overlap of LCH and another histiocytic disorder of a different type.

We present the case of a patient with $\mathrm{MH}$ representing LCH overlapping with ECD, who refused radical treatment. This report focused on the anterior pituitary hormones, assessed serially by dynamic testing during 2 years of follow-up, since such investigations have not been reported to date.

\section{Case presentation}

A 61-year-old man was hospitalised with persistent polyuria and polydipsia after a 2-year history of general fatigue. He also reported pain in both lower legs. Blood pressure, heart rate, and temperature were 125/86 $\mathrm{mmHg}$, 114 beats/min, and $38.6^{\circ} \mathrm{C}$, respectively. He had no contributory past or family history.

\section{Investigation}

Laboratory testing showed: white blood cell count, $10.7 \times 10^{9} / \mathrm{L}(10700 / \mu \mathrm{L}) ; \mathrm{C}$-reactive protein, $10.4 \times 10^{4}$ $\mu \mathrm{g} / \mathrm{L}(10.4 \mathrm{mg} / \mathrm{dL}) ;$ serum sodium, $143 \mathrm{mmol} / \mathrm{L}$ (143 $\mathrm{mEq} / \mathrm{L})$; plasma osmolality, $289 \mathrm{mmol} / \mathrm{kg}$ (289 mOsm/kg); and urine osmolality, $118 \mathrm{mmol} / \mathrm{kg}(118 \mathrm{mOsm} / \mathrm{kg})$. Urine volume was $>9 \mathrm{~L} /$ day with a low antidiuretic hormone level of $0.8 \mathrm{pmol} / \mathrm{L}(0.9 \mathrm{pg} / \mathrm{mL})$. Growth hormone $(\mathrm{GH})$, insulin-like growth factor-1 (IGF-1), and testosterone levels were decreased below normal levels (Table 1).

Results from the hypertonic saline infusion test (Table 2) and water deprivation test (Table 3) led to the diagnosis of CDI. Whereas GH deficiency (GHD) was diagnosed by an insulin tolerance test (ITT), other anterior pituitary hormones such as luteinising hormone (LH), follicle-stimulating hormone (FSH), adrenocorticotropic hormone $(\mathrm{ACTH})$, and thyroid-stimulating hormone (TSH) all showed normal secretion in response to dynamic testing (Tables 4 and 5). Baseline prolactin (PRL) was at the upper end of the normal range or slightly elevated, but the response to dynamic testing was preserved. The peak cortisol was $<496.6 \mathrm{nmol} / \mathrm{L}(18 \mu \mathrm{g} / \mathrm{dL})$ on the ITT and on the corticotropin-releasing hormone (CRH) dynamic test, but normal secretion of cortisol at $582.1 \mathrm{nmol} / \mathrm{L}(21.1$ $\mu \mathrm{g} / \mathrm{dL}$ ) was confirmed by the rapid ACTH dynamic test.

MRI of the brain showed that signal hyperintensities in the posterior pituitary lobe were slightly reduced on
Table 1 Laboratory data at the initial examination.

\begin{tabular}{|c|c|c|}
\hline Parameter & $\begin{array}{l}\text { Result } \\
\text { value }\end{array}$ & Reference range \\
\hline Haemoglobin (g/L) & 140 & $135-176$ \\
\hline White blood cells (×109/L) & 10.7 & $3.9-9.8$ \\
\hline Platelets $\left(\times 10^{9} / \mathrm{L}\right)$ & 637 & $131-362$ \\
\hline Blood urea nitrogen (mmol/L) & 3.9 & $2.9-7.9$ \\
\hline Creatinine $(\mu \mathrm{mol} / \mathrm{L})$ & 66.3 & $53.9-91.9$ \\
\hline Sodium (mmol/L) & 143 & $136-147$ \\
\hline Chloride (mmol/L) & 105 & 98-109 \\
\hline Potassium (mmol/L) & 3.9 & $3.6-5.0$ \\
\hline Alkaline phosphatase (IU/L) & 298 & $115-359$ \\
\hline y-Glutamyl transpeptidase (IU/L) & 44 & $0-70$ \\
\hline Aspartate transaminase (IU/L) & 20 & $10-40$ \\
\hline Alanine transaminase (IU/L) & 33 & $55-40$ \\
\hline Lactate dehydrogenase (IU/L) & 176 & $115-245$ \\
\hline Creatinine phosphokinase (IU/L) & 58 & $62-287$ \\
\hline Glucose (mmol/L) & 5.2 & $3.9-6.1$ \\
\hline Total protein (g/L) & 58 & $67-83$ \\
\hline Albumin (g/L) & 25 & $38-52$ \\
\hline C-reactive protein ( $\mu \mathrm{g} / \mathrm{L})$ & $10.4 \times 10^{4}$ & $<0.3 \times 10^{4}$ \\
\hline $\mathrm{GH}(\mu \mathrm{g} / \mathrm{L})$ & 0.19 & $<2.47$ \\
\hline IGF-1 (nmol/L) & 6.9 & $10.3-30.3$ \\
\hline LH (IU/L) & 3.81 & $0.79-5.72$ \\
\hline $\mathrm{FSH}(\mathrm{IU} / \mathrm{L})$ & 2.78 & $2.00-8.30$ \\
\hline Testosterone (nmol/L) & 2.46 & $4.54-30.20$ \\
\hline PRL $(\mu g / L)$ & 12.0 & 4.3-13.7 \\
\hline ACTH (pmol/L) & 2.7 & 1.6-13.9 \\
\hline Cortisol (nmol/L) & 438.6 & $195.1-540.7$ \\
\hline $\mathrm{TSH}(\mathrm{mlU} / \mathrm{L})$ & 0.70 & $0.50-5.00$ \\
\hline Free T3 (pmol/L) & 3.7 & $3.5-6.6$ \\
\hline Free T4 (pmol/L) & 13.3 & $11.6-21.9$ \\
\hline $\mathrm{ADH}(\mathrm{pmol} / \mathrm{L})$ & 0.8 & $<2.6$ \\
\hline Plasma osmolality (mmol/kg) & 289 & $275-290$ \\
\hline Urine osmolality (mmol/kg) & 118 & $50-1300$ \\
\hline
\end{tabular}

T1-weighted imaging (T1WI) (Fig. 1A1). Thickening of the pituitary stalk with homogeneous enhancement was also observed on postcontrast T1WI (Fig. 1A1 and B1). Potential causes of secondary CDI were investigated. High accumulation of 18 F-labelled fluorodeoxyglucose (FDG) on PET/CT showed osteosclerotic change in the skull, facial bones, spine, bilateral collarbones, bilateral scapulas, bilateral ribs, pelvis, and bones of the extremities, where ${ }^{18} \mathrm{~F}-\mathrm{FDG}$ was highly accumulated (Fig. 2). Moreover, CT showed partial thickening of the

Table 2 Hypertonic saline infusion test.

\begin{tabular}{|c|c|c|c|c|c|}
\hline Time (min) & $\mathbf{0}$ & 30 & 60 & 90 & 120 \\
\hline ADH (pmol/L) & 0.4 & 0.4 & 0.7 & 0.5 & 0.6 \\
\hline Sodium (mmol/L) & 147 & 154 & 156 & 159 & 163 \\
\hline $\begin{array}{l}\text { Plasma osmolality } \\
\text { (mmol/kg) }\end{array}$ & 301 & 310 & 315 & 320 & 325 \\
\hline $\begin{array}{l}\text { Urine osmolality } \\
\text { (mmol/kg) }\end{array}$ & 103 & 96 & 108 & 124 & 141 \\
\hline Urine volume $(\mathrm{mL})$ & - & 250 & 250 & 220 & 200 \\
\hline
\end{tabular}


Table 3 Water deprivation test (intrabolus vasopressin at $6.5 \mathrm{~h}$ ).

\begin{tabular}{l}
\hline Time $(\mathrm{h})$ \\
\hline ADH $(\mathrm{pmol} / \mathrm{L})$ \\
Sodium $(\mathrm{mmol} / \mathrm{L})$ \\
Plasma osmolality $(\mathrm{mmol} / \mathrm{kg})$ \\
Urine osmolality $(\mathrm{mmol} / \mathrm{kg})$ \\
Urine volume $(\mathrm{mL})$
\end{tabular}

\begin{tabular}{c}
\hline $\mathbf{0}$ \\
\hline 0.6 \\
154 \\
310 \\
126 \\
-
\end{tabular}

\begin{tabular}{c}
\hline $\mathbf{1}$ \\
\hline 0.6 \\
155 \\
313 \\
154 \\
150
\end{tabular}

\begin{tabular}{c}
\hline $\mathbf{2}$ \\
\hline 0.5 \\
157 \\
314 \\
181 \\
100 \\
\hline
\end{tabular}

\begin{tabular}{ccc}
\hline $\mathbf{3}$ & & $\mathbf{4}$ \\
\cline { 1 - 1 } $\begin{array}{c}n \\
156\end{array}$ & & 0.7 \\
315 & & 317 \\
238 & & 232 \\
80 & & 100 \\
\hline
\end{tabular}

\begin{tabular}{c}
\hline $\mathbf{5}$ \\
\hline 0.4 \\
156 \\
317 \\
269 \\
80 \\
\hline
\end{tabular}

\begin{tabular}{c}
\hline $\mathbf{6}$ \\
\hline 0.5 \\
158 \\
318 \\
249 \\
80 \\
\hline
\end{tabular}

\begin{tabular}{|c|c|}
\hline 6.5 & 7.5 \\
\hline$<0.4$ & - \\
\hline 158 & - \\
\hline 318 & - \\
\hline 264 & 374 \\
\hline 35 & 75 \\
\hline
\end{tabular}

ascending and abdominal aortic walls, stenosis of the right iliac artery, and occlusion of the left common iliac artery (Fig. 3A1).

Bone biopsy of the tibia showed fibrosis with numerous mononuclear foamy cells, scattered Toutontype multinucleated giant cells, and small cells. Immunostaining showed that foamy cells were positive for CD68 and S100 protein and negative for CD1a. In contrast, small cells were positive for CD1a. Based on the clinical, radiological, and histopathological context, the patient was diagnosed with ECD.

The patient developed small red papules mainly on the skin of the trunk and upper limbs 3 months after the initial visit. Skin punch biopsy showed numerous mononuclear cells with eosinophilic cytoplasm in the epidermis and superficial dermis. These cells were positive for S100 protein and CD1a and negative for CD68, consistent with a diagnosis of LCH. Therefore, the final diagnosis was $\mathrm{MH}$ showing features of both ECD and $\mathrm{LCH}$.

\section{Treatment}

No radical treatment was given for $\mathrm{MH}$, based on the wishes of the patient. CDI was replaced by $60 \mu \mathrm{g}$ of oral 1-desamino-8-D-arginine vasopressin. Symptoms such as polyuria and polydipsia were improved, and urine volume was decreased to less than $3 \mathrm{~L} /$ day.

\section{Outcome and follow-up}

Anterior pituitary dynamic function tests were performed serially during 2 years of follow-up after the initial visit (Tables 4 and 5). The secretion of GH was impaired on the ITT 1 year later, but recovered to the normal level $(>3 \mu \mathrm{g} / \mathrm{L}(>3 \mathrm{ng} / \mathrm{mL})) 2$ years later (Table 5$)$. Despite the lack of radical treatment for the primary disease, responses of other anterior pituitary hormones such as LH, FSH, TSH, and PRL to dynamic tests were conserved. Although ACTH did not reach the reference value in the CRH test 1 and 2 years later (Table 4), ACTH showed a normal response on

Table 4 GnRH-CRH-TRH dynamic test.

\begin{tabular}{l}
\hline Time $(\mathrm{min})$ \\
\hline Initial examination \\
PRL $(\mu \mathrm{g} / \mathrm{L})$ \\
$\mathrm{LH}(\mathrm{IU} / \mathrm{L})$ \\
FSH $(\mathrm{IU} / \mathrm{L})$ \\
ACTH $(\mathrm{pmol} / \mathrm{L})$ \\
Cortisol $(\mathrm{nmol} / \mathrm{L})$ \\
TSH $(\mathrm{mlU} / \mathrm{L})$ \\
1 year later \\
$\mathrm{PRL}(\mu \mathrm{g} / \mathrm{mL})$ \\
$\mathrm{LH}(\mathrm{IU} / \mathrm{mL})$ \\
FSH $(\mathrm{IU} / \mathrm{mL})$ \\
ACTH $(\mathrm{pmol} / \mathrm{L})$ \\
Cortisol $(\mathrm{nmol} / \mathrm{L})$ \\
TSH $(\mathrm{mlU} / \mathrm{L})$ \\
2 years later \\
$\mathrm{PRL}(\mu \mathrm{g} / \mathrm{L})$ \\
$\mathrm{LH}(\mathrm{IU} / \mathrm{L})$ \\
FSH $(\mathrm{IU} / \mathrm{L})$ \\
ACTH $(\mathrm{pmol} / \mathrm{L})$ \\
Cortisol $(\mathrm{nmol} / \mathrm{L})$ \\
TSH $(\mathrm{mlU} / \mathrm{L})$
\end{tabular}

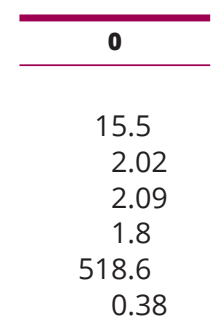

\begin{tabular}{c}
\hline $\mathbf{1 5}$ \\
\hline 74.0 \\
8.70 \\
2.99 \\
3.9 \\
551.7 \\
5.84
\end{tabular}

\begin{tabular}{c}
$\mathbf{3 0}$ \\
\hline \\
61.8 \\
11.13 \\
3.46 \\
4.6 \\
620.7 \\
6.42
\end{tabular}

\section{7}

2.98

5.37

2.2

259.3

1.05

11.0

4.87

5.02

3.0

251.0

1.14
110.0

11.00

7.98

2.5

281.3

5.65

79.3

10.50

6.42

3.2

297.9

5.51
93.7

15.22

8.95

3.4

289.7

6.47

67.7

12.76

7.36

5.2

331.0

6.47

\begin{tabular}{c}
\hline $\mathbf{6 0}$ \\
\hline 37.4 \\
12.37 \\
3.91 \\
2.6 \\
550.0 \\
4.49
\end{tabular}

\begin{tabular}{c}
\hline $\mathbf{9 0}$ \\
\hline 25.8 \\
10.71 \\
4.09 \\
2.4 \\
491.0 \\
3.07
\end{tabular}

\begin{tabular}{c}
\hline $\mathbf{1 2 0}$ \\
\hline 19.5 \\
9.97 \\
3.94 \\
1.9 \\
510.3 \\
1.99
\end{tabular}

\section{3}

14.66

10.06

3.1

322.8

4.89
41.1

14.06

9.06

1.9

278.6

3.75

33.5

12.52

7.29

2.4

314.5

4.08
33.3

11.50

9.77

1.8

242.8

2.72

25.9

11.94

7.92

3.2

297.9

3.28

$\mathrm{CRH}$, corticotropin-releasing hormone; $\mathrm{GnRH}$, gonadotropin-releasing hormone; TRH, thyrotropin-releasing hormone. 
Table 5 Insulin tolerance test.

\begin{tabular}{|c|c|c|c|c|}
\hline Time (min) & 0 & 30 & 60 & 90 \\
\hline \multicolumn{5}{|l|}{ Initial examination } \\
\hline Glucose (mmol/L) & 6.2 & 2.8 & 4.7 & 5.3 \\
\hline $\mathrm{GH}(\mu \mathrm{g} / \mathrm{L})$ & 0.89 & 2.73 & 2.10 & 1.30 \\
\hline ACTH (pmol/L) & 1.1 & 2.0 & 3.1 & 1.5 \\
\hline Cortisol (nmol/L) & 273.1 & 259.3 & 397.2 & 328.3 \\
\hline \multicolumn{5}{|l|}{1 year later } \\
\hline Glucose (mmol/L) & 5.5 & 2.6 & 3.7 & 4.7 \\
\hline $\mathrm{GH}(\mu \mathrm{g} / \mathrm{L})$ & 1.12 & 0.96 & 1.89 & 2.84 \\
\hline ACTH (pmol/L) & 1.8 & 4.2 & 19.3 & 5.4 \\
\hline Cortisol (nmol/L) & 187.6 & 209.7 & 460.7 & 400.0 \\
\hline \multicolumn{5}{|l|}{2 years later } \\
\hline Glucose $(\mathrm{mmol} / \mathrm{L})$ & 5.9 & 2.2 & 2.6 & 3.4 \\
\hline $\mathrm{GH}(\mu \mathrm{g} / \mathrm{L})$ & 1.57 & 3.03 & 3.14 & 3.63 \\
\hline ACTH (pmol/L) & 3.2 & 9.0 & 12.6 & 7.1 \\
\hline Cortisol (nmol/L) & 231.7 & 284.1 & 383.4 & 342.1 \\
\hline
\end{tabular}

the ITT (Table 5) (reference value: ACTH $\geq 2$-fold of baseline value on both tests). The testosterone level was decreased below the normal level on the initial examination (Table 1), but it was normalized at $11.3 \mathrm{nmol} / \mathrm{L}(3.27 \mathrm{ng} /$ $\mathrm{mL}) 6$ months after the initial examination.

MRI did not show any particular interval changes other than the disappearance of signal hyperintensity in the posterior pituitary lobe (Fig. 1A2, A3, B2 and B3). In contrast, CT showed progression of abdominal aortic involvement ('coated aorta') and extension of retroperitoneal soft tissue around the kidney ('hairy kidney') (Fig. 3A2 and A3).

\section{Discussion}

Histiocytoses are rare disorders characterised by the accumulation of macrophages and dendritic cells derived from a myeloid lineage (1). The Histiocyte Society developed a new classification in 2016, and five categories have been proposed: groups $\mathrm{L}, \mathrm{C}, \mathrm{M}, \mathrm{R}$, and $H$ (1). The L (Langerhans) group consists of LCH, ECD, and extracutaneous juvenile xanthogranuloma, and the present patient was thus assigned to the L group. It has been reported that the annual incidence of $\mathrm{LCH}$ in children younger than 15 years of age is around 5 to $9 / 10^{6}$ and $1 / 10^{6}$ in patients older than 15 years of age (1). Though the exact prevalence of ECD is unknown, between 500 and 1000 individuals with ECD have been described in the medical literature to date. The concomitant occurrence of two distinct histiocytoses in the same patient is exceptional, but the association of LCH with ECD seems to be the most frequent (2). Both LCH and ECD share common clinical manifestations, such as CDI, and nearly $20 \%$ of patients with ECD also display LCH lesions $(2,3)$. The present patient was first diagnosed with ECD based on the clinical, radiological, and histopathological context. However, the patient subsequently presented with a skin rash atypical for ECD and histopathology in these lesions was consistent with the diagnosis of LCH. Therefore, this patient was diagnosed with $\mathrm{MH}$ representing $\mathrm{LCH}$ overlapping with ECD.

To the best of our knowledge, no previous reports have described serial assessments of pituitary anterior hormones by dynamic testing during follow-up of $\mathrm{MH}$. In addition, because the patient did not wish to undergo radical treatment for $\mathrm{MH}$, the course of the hormones during follow-up would reflect the natural course of $\mathrm{MH}$. We thus believe that the present case is valuable from these perspectives. At the time of diagnosis of ECD, CDI and GHD had already developed in this patient.

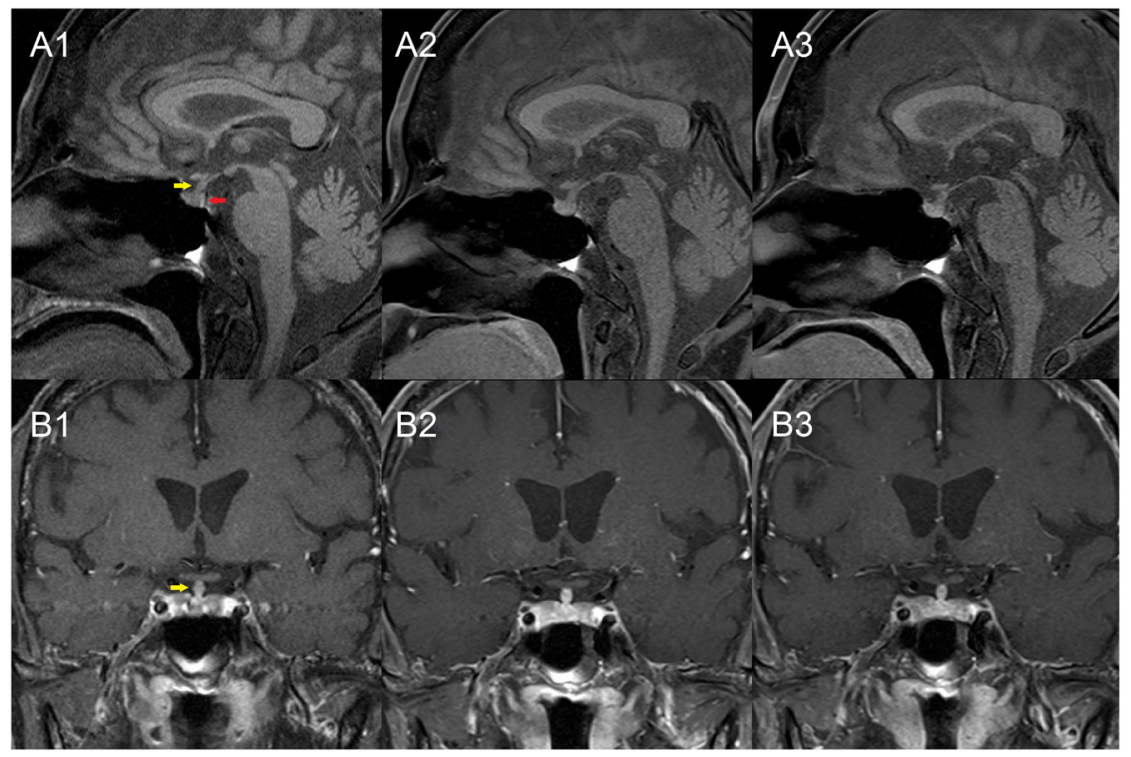

Figure 1

Brain MRI. A1/B1, initial assessment; A2/B2, 1 year later; A3/B3, 2 years later. Signal hyperintensity in the posterior pituitary lobe is slightly reduced on T1WI (A1, red arrow) at initial assessment and disappeared on subsequent images (A2 and A3). Thickening of the pituitary stalk with

homogeneous intense enhancement is observed on postcontrast T1WI (A1 and B1, yellow arrows), with no particular interval changes on follow-up MRI (B2 and B3). 


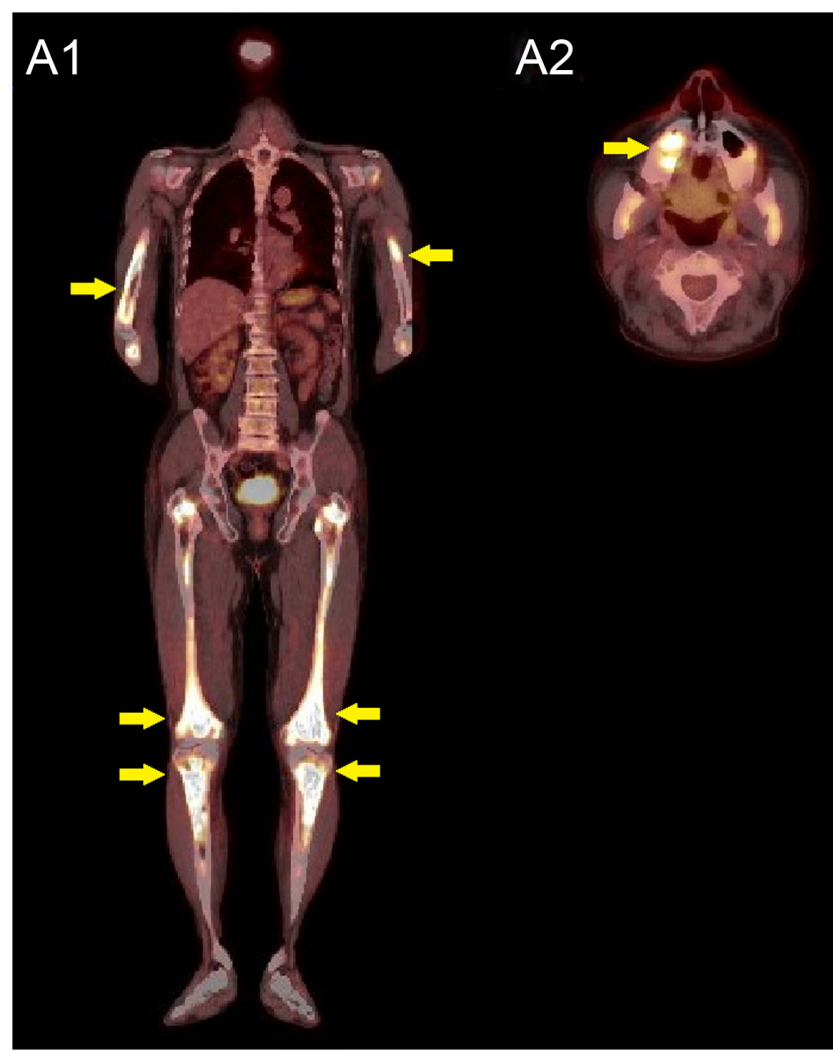

Figure 2

Results of ${ }^{18} \mathrm{~F}$-FDG-PET. Representative images are shown. FDG appears highly accumulated in the long bones of the extremities (A1) and maxilla (A2).

CDI has been reported as a frequent endocrinological manifestation in ECD and $\mathrm{LCH}$, and the prevalences of CDI are similar in both diseases, at around 30\% (4, 5, 6, $7,8)$. Anterior pituitary dysfunction is also observed in more than $50 \%$ of cases of both diseases in which GHD is the most frequent deficit $(4,5,6)$. Interestingly, no other anterior pituitary dysfunctions emerged in the present case during 2 years of follow-up, despite the lack of radical treatment. Moreover, GH secretion, which was impaired on the ITT 1 year later, recovered to the normal value on the ITT 2 years later. This contrasts with a study evaluating endocrine manifestations in 64 patients with ECD on treatment, in which pituitary deficits appeared to progress during 13.7 months of follow-up (4). Manaka et al. also reported a patient with ECD treated with interferon $\alpha$ who newly developed secondary hypothyroidism due to pituitary dysfunction during 4 years of follow-up (9).

Drier et al. suggested that brain MRI showed hypothalamic-pituitary axis involvement in more than $50 \%$ of patients with ECD (10). Brain MRI in the present case demonstrated thickening of the pituitary stalk with homogeneous, intense enhancement with a slight decrease in hyperintense signalling in the posterior pituitary lobe. PRL usually increases as a result of suprasellar dysfunction, and baseline PRL was at the upper end of the normal range or slightly elevated in the present case. Moreover, anterior pituitary hormones other than GH responded normally to ITTs. Taken together with the MRI findings, the patient would have had a disorder at the level of the pituitary stalk. Interestingly, MRI did not demonstrate particular interval changes in pituitary stalk involvement during 2 years of follow-up despite the absence of radical treatment. In contrast, vascular and retroperitoneal involvements were exacerbated on wholebody CT.

In conclusion, the case of a patient with $\mathrm{MH}$ in whom anterior pituitary hormones were serially evaluated by dynamic tests was presented. No anterior pituitary dysfunction other than GHD emerged during 2 years of follow-up, despite the lack of radical therapy for MH. This report should help clinicians develop a better understanding of $\mathrm{MH}$.

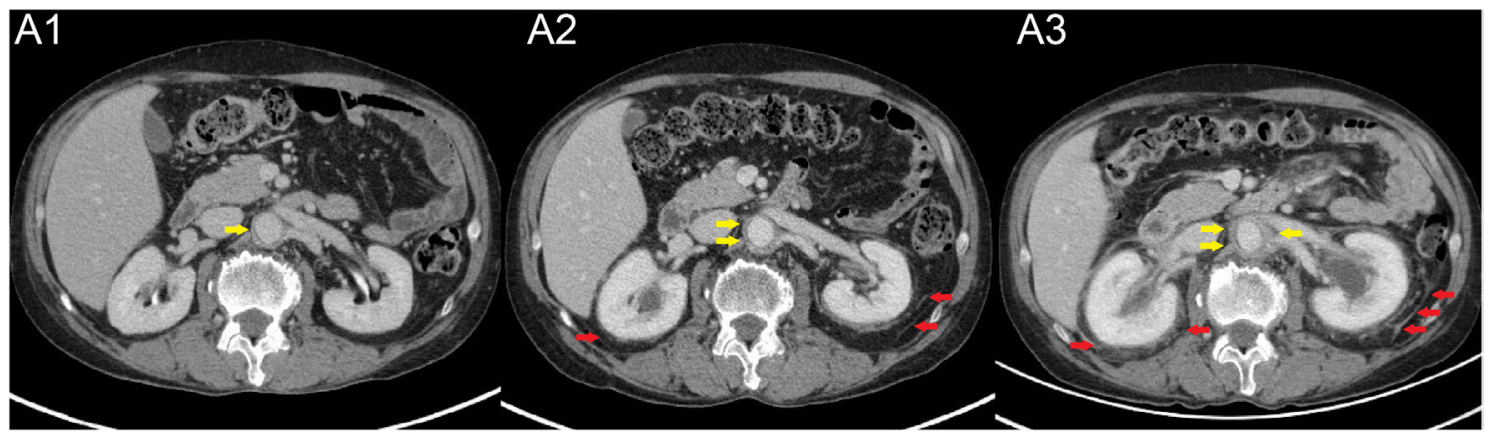

Figure 3

Whole-body CT. A1, initial assessment; A2, 1 year later; A3, 2 years later. Representative images are shown. Initial image shows partial thickening of the abdominal aortic wall (A1, yellow arrow). Abdominal aortic involvement shows progression (A2 and A3, yellow arrows), and extension of retroperitoneal soft tissue around the kidney on subsequent images ( $\mathrm{A} 2$ and $\mathrm{A} 3$, red arrows). 


\section{Declaration of interest}

The authors declare that there is no conflict of interest that could be perceived as prejudicing the impartiality of this case report.

\section{Funding}

This research did not receive any specific grant from any funding agency in the public, commercial or not-for-profit sector

\section{Patient consent}

Written, informed consent was obtained for publication of the case report.

\section{Author contribution statement}

$\mathrm{KI}, \mathrm{YY}, \mathrm{RN}, \mathrm{MF}, \mathrm{YK}, \mathrm{AM}$, and $\mathrm{HY}$ were involved in the clinical care of the patient. NT assessed pathological findings. KT and MK provided advice on diagnosis and treatment in this case. $\mathrm{KI}$ and $\mathrm{HY}$ were involved in writing the manuscript.

\section{References}

1 Emile JF, Abla O, Fraitag S, Horne A, Haroche J, Donadieu J, RequenaCaballero L, Jordan MB, Abdel-Wahab O, Allen CE, et al. Revised classification of histiocytoses and neoplasms of the macrophagedendritic cell lineages. Blood 2016127 2672-2681. (https://doi. org/10.1182/blood-2016-01-690636)

2 Hervier B, Haroche J, Arnaud L, Charlotte F, Donadieu J, Néel A, Lifermann F, Villabona C, Graffin B, Hermine O, et al. Association of both Langerhans cell histiocytosis and Erdheim-Chester disease linked to the BRAFV600E mutation. Blood 2014124 1119-1126. (https://doi.org/10.1182/blood-2013-12-543793)
3 Nabi S, Arshad A, Jain T, Virk F, Gulati R \& Awdish R. A rare case of Erdheim-Chester disease and Langerhans cell histiocytosis overlap syndrome. Case Reports in Pathology 20152015 949163. (https://doi. org/10.1155/2015/949163)

4 Courtillot C, Laugier Robiolle S, Cohen Aubart F, Leban M, RenardPenna R, Drier A, Charlotte F, Amoura Z, Touraine P \& Haroche J. Endocrine manifestations in a monocentric cohort of 64 patients with Erdheim-Chester disease. Journal of Clinical Endocrinology and Metabolism 2016101 305-313. (https://doi.org/10.1210/jc.2015-3357)

5 Makras P, Alexandraki KI, Chrousos GP, Grossman AB \& Kaltsas GA. Endocrine manifestations in Langerhans cell histiocytosis. Trends in Endocrinology and Metabolism 200718 252-257. (https://doi. org/10.1016/j.tem.2007.06.003)

6 Goyal G, Young JR, Koster MJ, Tobin WO, Vassallo R, Ryu JH, Davidge-Pitts CJ, Hurtado MD, Ravindran A, Sartori Valinotti JC et al. The Mayo Clinic Histiocytosis Working Group Consensus Statement for the diagnosis and evaluation of adult patients with histiocytic neoplasms: Erdheim-Chester disease, Langerhans cell histiocytosis, and Rosai-Dorfman disease. Mayo Clinic Proceedings 201994 2054-2071. (https://doi.org/10.1016/j.mayocp.2019.02.023)

7 Toro Galván S, Planas Vilaseca A, Michalopoulou Alevras T, Torres Díaz A, Suárez Balaguer J \& Villabona Artero C. Endocrine changes in histiocytosis of the hypothalamic-pituitary axis. Endocrinologia y Nutricion 201562 72-79. (https://doi.org/10.1016/j. endonu.2014.10.004)

8 Kaltsas GA, Powles TB, Evanson J, Plowman PN, Drinkwater JE, Jenkins PJ, Monson JP, Besser GM \& Grossman AB. Hypothalamopituitary abnormalities in adult patients with langerhans cell histiocytosis: clinical, endocrinological, and radiological features and response to treatment. Journal of Clinical Endocrinology and Metabolism 200085 1370-1376. (https://doi.org/10.1210/jcem.85.4.6501)

9 Manaka K, Makita N \& Iiri T. Erdheim-Chester disease and pituitary involvement: a unique case and the literature. Endocrine Journal 2014 61 185-194. (https://doi.org/10.1507/endocrj.ej13-0419)

10 Drier A, Haroche J, Savatovsky J, Godenèche G, Dormont D, Chiras J, Amoura Z \& Bonneville F. Cerebral, facial, and orbital involvement in Erdheim-Chester disease: CT and MR imaging findings. Radiology 2010255 586-594. (https://doi.org/10.1148/ radiol.10090320)

Received in final form 8 April 2021 Accepted 26 April 2021 